\title{
Assessment of serum uric acid levels in patients with cervical intraepithelial neoplasia in Benin City
}

\author{
Kenneth Atoe, ${ }^{1,2,3}$ Augustine Onovuakpo Eguvbe ${ }^{1}$ \\ ${ }^{1}$ Department of Chemical Pathology, Edo University, Iyamho, Edo State; ${ }^{2}$ Applied Environmental Bioscience \\ and Public Research Group, University of Benin, Benin City; ${ }^{3}$ Phytomedicine and Drug Discovery Research \\ Group, Department of Plant Biology and Biotechnology, University of Benin, Benin City, Nigeria
}

\begin{abstract}
Elevated Uric acid levels in humans have been associated with cancer, though the pathogenic mechanism is still unclear. The present study attempts to investigate if elevated uric acid levels could be used to investigate the pre-malignant lesions leading to cervical cancer. The study which was carried out at the Department of Obstetrics and Gynaecology, University of Benin Teaching Hospital Benin City and Department of Chemical Pathology, Edo University Iyamho, Edo state Nigeria, between August, 2017 and January 2019, examined the capacity of detecting Cervical Intraepithelial Neoplasia (CIN) early with serum uric acid in order to increase the chances of survival of women at risk. A total of 197 female participants were recruited for the study. Based on histological diagnosis, they were grouped as CIN 1, CIN 2 and CIN 3. The control group were negative for CIN. Venous blood was obtained from participants and serum uric acid levels were determined using
\end{abstract}

Correspondence: Kenneth Atoe, Department of Chemical Pathology, Edo University, Iyamho, Edo State, Nigeria.

E-mail: atoe.kenneth@edouniversity.edu.ng

Key words: Cervix; cancer; uric acid; neoplasia; metabolic medicine.

Conflict of interest: The authors declare no conflicts of interests

Ethics approval and conflict of interest: All procedures performed in studies involving human participants were in accordance with the ethical standards of the Institutional Research Committee and with the 1964 Helsinki declaration and its latest amendment. Informed consents were obtained from all study participants prior to study

Consent for publication: The patients gave their consent to the publication.

Availability of data and materials: All data generated or analyzed during this study are included in this published article

Received for publication: 9 August 2020.

Revision received: 13 January 2021.

Accepted for publication: 22 January 2021.

This work is licensed under a Creative Commons Attribution NonCommercial 4.0 License (CC BY-NC 4.0).

(C) Copyright: the Author(s), 2021

Licensee PAGEPress, Italy

Annals of Clinical and Biomedical Research 2021; 2:99

doi:10.4081/acbr.2021.99 standard laboratory methods. The benchmark for serum uric acid levels in diagnosing CIN presented in this study was at 6.55 $\mathrm{mg} / \mathrm{dL}$. The probability that uric acid level higher than $6.55 \mathrm{mg} / \mathrm{dL}$ indicate the disease probabilty was $93.1 \%$. The age category within the CIN group with the highest level of uric acid was 31-40 years $(10.86 \mathrm{mg} / \mathrm{dL})$. The use of serum uric acid as an excellent biomarker for the diagnosis of CIN is therefore suggested due to its high sensitivity

\section{Introduction}

The incidence of invasive cervical cancer in Sub-Sahara Africa is on the increase. This is the most common cancer in women globally. ${ }^{1}$ It is one of the leading cause of death among the female population in Nigeria. ${ }^{2}$ This type of cancer being a slow progressive disease can take from one to numerous years to progress from a precancerous state to cancer. ${ }^{3}$ The precancerous state is known as cervical intraepithelial neoplasia (CIN) and is categorized according to the cell abnormality levels CIN 1, CIN 2 and CIN 3. ${ }^{4}$

Metabolic related factors have been suggested in the onset of cancer, including hyperuricemia. ${ }^{5}$ Recent evidence demonstrated that elevated serum uric acid is associated with a high risk of cancer incidence. ${ }^{6}$ There is dearth of information on the association between uric acid levels and cervical cancer. Uric acid is the final metabolite of purine metabolism and is associated with significant health problems but it can be harnessed into a life line for millions of women who are potentially at risk of cervical cancer.

Hyperuricemia is caused by abnormal metabolism of uric acid, due to either rapid cell turnover as seen in malignancy or poor clearance in patients with renal impairment. ${ }^{7}$ It can be thought therefore that elevated uric acid does not cause cancer but the very early stage of cell malfunctioning causes hyperuricemia. Although serum uric acid possesses antioxidant properties, increased levels of serum uric acid can lead to inflammatory response in human body and thus promote the occurrence of tumors. ${ }^{8}$ Consequently, serum uric acid elevation can be exploited as a biomarker of disease risk at the connection of these critical pathophysiologic developments. Investigations to explore the diagnostic potential of uric acid as an early biomarker for the diagnosis of Cervical Intraepithelial Neoplasia (CIN) is critical in the mitigation of cervical cancer. The study therefore examined the possibility of exploring the benefits of elevated uric acid in early detection of CIN.

\section{Materials and Methods}

Study location

The study was conducted in the Department of Obstetrics and Gynaecology, University of Benin Teaching Hospital (UBTH) as 
well as the Metabolic Research Unit of the Department of Chemical Pathology, Edo University Iyamho, Edo State, Nigeria, where biochemical analysis of the research participants was done

\section{Participants}

A total of 197 female participants were recruited for the study from August 2017 to January 2019. Based on histological diagnosis, they were grouped as CIN 1, CIN 2 and CIN 3. The participants in the control group were negative for CIN. Cases included patients with histological diagnosis of cervical intraepithelial neoplasm and abnormal Pap smear referred from Gynaecology Clinic, General Practice Clinic, Community Development Clinic in University of Benin Teaching Hospital (UBTH) and also referrals for Colposcopy from private hospitals in Benin City.

\section{Inclusion and exclusion criteria}

The inclusion criteria were patients aged between 18 and 75 years and with histological diagnosis of cervical intraepithelial neoplasm and abnormal Pap smear referred from Gynaecology Clinic, General Practice Clinic, Community Development Clinic in University of Benin Teaching Hospital. The exclusion criteria for this study included patients with kidney diseases, lead poisoning, tumour (e.g. leukaemia, myeloma), psoriasis, alcoholism, drugs (e.g. salicylate, thiazide diuretics), trauma. Patients on radiotherapy and chemotherapy were also excluded.

\section{Methodology}

Venipuncture was done for all the participants for collection of blood sample for biochemical analysis. Five $\mathrm{mL}$ of blood samples was collected into a plain tube, allowed to clot and retract, thereafter centrifuged at $2000 \mathrm{rpm}$ for 15 minutes. The serum was collected with Pasteur pipette into a plain tube and then stored at about $-4{ }^{\circ} \mathrm{C}$ until the biochemical analysis was carried out. Uric acid was determined using the Enzymatic Colorimetric method. In this method, the enyzme uricase transforms uric acid in the sample into Allantoin, Carbon dioxide and Hydrogen peroxide. By the action of peroxidase and in the presence of phenol-derivative, DHBS and 4-Aminoantipyrine, Hydrogen peroxide gives a coloured indicator reaction, which can be measured at $520 \mathrm{~nm}$. The increasing in absorbance correlates with the uric acid concentration of the sample. ${ }^{9}$

\section{Data analysis}

Data collected were analyzed using SPSS version 20. Results were presented using Tables, Plates and Graphs. Quantitative variables were expressed as mean \pm standard deviation while qualitative data were presented using frequencies and proportions.

\section{Results}

The Socio-demographic data of the study participants showed that out of 197 participants recruited for the study, 53 were negative for CIN lesions, compared to 144 that had CIN lesion based on histological diagnosis (Table 1). The participants were also grouped according to age, with most of the participants in both

Table 1. Socio-demographic characteristics of the study population.

\begin{tabular}{|c|c|c|c|c|c|c|c|}
\hline & & $\begin{array}{l}\text { CIN } \\
\text { (n) }\end{array}$ & $\begin{array}{l}44) \\
(\%)\end{array}$ & $\begin{array}{r}\text { Contro } \\
\text { (n) }\end{array}$ & $\begin{array}{c}n=53) \\
(\%)\end{array}$ & $x^{2}$ & p-value \\
\hline CIN.Staus & $\begin{array}{l}\text { Normal } \\
\text { Stage } 1 \\
\text { Stage } 2 \\
\text { Stage } 3\end{array}$ & $\begin{array}{c}0 \\
45 \\
49 \\
50\end{array}$ & $\begin{array}{c}0 \\
22.8 \\
24.9 \\
25.4\end{array}$ & $\begin{array}{c}53 \\
0 \\
0 \\
0\end{array}$ & $\begin{array}{c}26.9 \\
0 \\
0 \\
0\end{array}$ & 0.463 & 0.925 \\
\hline Age group (years) & $\begin{array}{l}31-40 \\
41-50 \text { yrs } \\
51-60 \text { yrs } \\
61-70 \text { yrs } \\
>70 \text { yrs }\end{array}$ & $\begin{array}{l}17 \\
32 \\
56 \\
10 \\
29\end{array}$ & $\begin{array}{c}11.8 \\
22.2 \\
38.9 \\
6.9 \\
20.1\end{array}$ & $\begin{array}{c}15 \\
10 \\
20 \\
8 \\
0\end{array}$ & $\begin{array}{c}28.3 \\
18.9 \\
37.7 \\
15.1 \\
0\end{array}$ & 5.784 & 0.216 \\
\hline Educational Stage & $\begin{array}{l}\text { Primary Ed. } \\
\text { Secondary Ed. } \\
\text { Tertiary Ed. }\end{array}$ & $\begin{array}{l}58 \\
16 \\
70\end{array}$ & $\begin{array}{l}40.3 \\
11.1 \\
48.6\end{array}$ & $\begin{array}{c}5 \\
26 \\
22\end{array}$ & $\begin{array}{c}9.4 \\
49.1 \\
41.5\end{array}$ & 2 & 0.368 \\
\hline Parity & $\begin{array}{l}1 \\
2 \\
3 \\
4 \\
5 \\
6 \\
7 \\
8 \\
11\end{array}$ & $\begin{array}{c}0 \\
6 \\
24 \\
38 \\
32 \\
19 \\
0 \\
22 \\
3\end{array}$ & $\begin{array}{c}0 \\
4.2 \\
16.7 \\
26.4 \\
22.2 \\
13.2 \\
0 \\
15.3 \\
2.1\end{array}$ & $\begin{array}{c}9 \\
0 \\
11 \\
17 \\
6 \\
8 \\
2 \\
0 \\
0\end{array}$ & $\begin{array}{c}17 \\
0 \\
20.8 \\
32.1 \\
11.3 \\
15.1 \\
3.8 \\
0 \\
0\end{array}$ & 11.501 & 0.175 \\
\hline Unsuccessful conception & $\begin{array}{l}0 \\
1 \\
2 \\
7\end{array}$ & $\begin{array}{c}142 \\
0 \\
1 \\
1\end{array}$ & $\begin{array}{c}98.6 \\
0 \\
0.7 \\
0.7\end{array}$ & $\begin{array}{l}49 \\
4 \\
0 \\
0\end{array}$ & $\begin{array}{c}92.5 \\
7.5 \\
0 \\
0\end{array}$ & 4.386 & 0.223 \\
\hline Marriage type & $\begin{array}{l}\text { Monogamy } \\
\text { Polygamy }\end{array}$ & $\begin{array}{l}127 \\
17\end{array}$ & $\begin{array}{l}88.2 \\
11.8\end{array}$ & $\begin{array}{l}37 \\
16\end{array}$ & $\begin{array}{l}69.8 \\
30.2\end{array}$ & 2.4 & 0.121 \\
\hline Smoking habit & $\begin{array}{l}\text { Smokers } \\
\text { Non Smokers }\end{array}$ & $\begin{array}{l}46 \\
98\end{array}$ & $\begin{array}{l}31.9 \\
68.1\end{array}$ & $\begin{array}{c}7 \\
46\end{array}$ & $\begin{array}{l}13.2 \\
86.8\end{array}$ & 2.4 & 0.121 \\
\hline History of usage of OCP & $\begin{array}{l}\text { No history } \\
<1 \text { year } \\
1-3 \text { years } \\
4-6 \text { years } \\
>6 \text { years }\end{array}$ & $\begin{array}{c}66 \\
68 \\
4 \\
0 \\
6\end{array}$ & $\begin{array}{c}45.8 \\
47.2 \\
2.8 \\
0 \\
4.2\end{array}$ & $\begin{array}{c}24 \\
9 \\
5 \\
12 \\
3\end{array}$ & $\begin{array}{c}45.3 \\
17 \\
9.4 \\
22.6 \\
5.7\end{array}$ & 5.564 & 0.234 \\
\hline
\end{tabular}


control and CIN groups belonging to the 51-60 years of age category. The mean uric acid levels in the control group was 5.68 $\mathrm{mg} / \mathrm{dL}$, whereas participants histologically diagnosed with CIN 3 had a mean uric acid level of $10.55 \mathrm{mg} / \mathrm{dL}$ (Table 2). Participants diagnosed with CIN 1 and 2 had uric acid levels of $7.68 \mathrm{mg} / \mathrm{dL}$ and $7.36 \mathrm{mg} / \mathrm{dL}$ respectively. The result in Figure 1 defined the Receiver Operator Characteristic (ROC) curve for Uric acid benchmark for possible use as a biomarker to diagnose CIN. The best model presented in this study of serum uric acid levels for diagnosing CIN was at $6.55 \mathrm{mg} / \mathrm{dL}$ (Table 3 ). This model proved to be a sensitive and specific biomarker as presented in Table 4. The sensitivity of uric acid as a marker was $93.8 \%$ while the specificity was $81.1 \%$. The probability that serum uric acid level higher than $6.55 \mathrm{mg} / \mathrm{dL}$ indicates the disease (PPV) was $93.1 \%$. However, the possibility that serum uric acid level $<6.55 \mathrm{mg} / \mathrm{dL}$ indicates the absence of CIN (NPV) was $82.7 \%$.

Uric acid levels of the control and CIN subjects were assessed according to age (Table 5). There were significant differences between the serum uric acid levels of healthy participants in all age categories examined. There were 20 subjects within 51-60 years of age histologically classed in the control group with uric acid level of $7.34 \mathrm{mg} / \mathrm{dL}$ while 15 individuals in the control group of ages 3140 years had $5.84 \mathrm{mg} / \mathrm{dL}$ uric acid level. In the histologically diagnosed CIN group, all 144 subjects across all age categories had uric acid level statistically higher than the benchmark $6.55 \mathrm{mg} / \mathrm{dL}$. Fifty-six women of ages 51-60 years in the CIN group had 10.14 $\mathrm{mg} / \mathrm{dL}$ uric acid level, 32 subjects in the CIN group within the ages of 41-50 years had uric acid level of $7.71 \mathrm{mg} / \mathrm{dL}$. The age category within the CIN group with the highest serum levels of uric acid were 31-40 years and 51-60 years (10.86 and $10.14 \mathrm{mg} / \mathrm{dL}$ respectively). All participants above 70 years of age ( 29 women) were histologically diagnosed of cervical intraepithelial lesions and had a uric acid level of $8.30 \mathrm{mg} / \mathrm{dL}$. The participants of this study were separated into CIN and control groups by the gold standard (Pap smear test) and by serum uric acid levels (Table 6). By gold standard, 144 women had CIN while 53 participants were healthy whereas by serum elevated uric acid, 145 women were diagnosed with CIN and 52 individuals were suggested healthy.

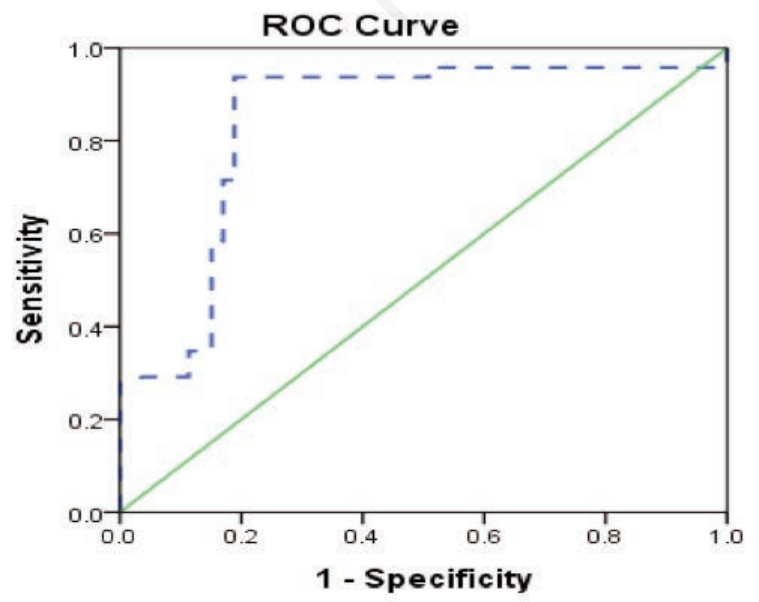

Figure 1. Receiver operator curve for uric acid in the possible diagnosis of CIN.

\section{Discussion}

The sensitivity of a biomarker is the probability that the test results will be positive if the disease is present. ${ }^{10}$ Based on the result presented by the ROC curve, uric acid was highly sensitive to CIN and suggested useful as an early marker (Tables 3 and 4).

Table 2. Mean uric acid levels in the study participants.

\begin{tabular}{lcc} 
& (n) & Uric acid $(\mathrm{mg} / \mathrm{d} / \mathrm{L})$ \\
Normal & 53 & $5.68 \mathrm{a}$ \\
Stage 1 & 45 & $7.68 \mathrm{~b}$ \\
\hline Stage 2 & 49 & $7.36 \mathrm{~b}$ \\
Stage 3 & 50 & $10.55 \mathrm{c}$ \\
\hline F-stat & - & 67.634 \\
p-value & - & $<0.001$
\end{tabular}

The mean $p$ values with similar alphabet letters do not differ from each other $(\mathrm{p}>0.05)$.

Table 3. Coordinates of the receiver operator curve.

\begin{tabular}{|c|c|c|c|}
\hline $\begin{array}{l}\text { Coordinates of the Curve } \\
\text { Positive if Greater } \\
\text { Than or Equal To }\end{array}$ & Sensitivity & Specificity & Difference \\
\hline 2.9000 & 1.000 & 1.000 & 0 \\
\hline 6.3000 & 0.938 & 0.321 & 0.617 \\
\hline 6.4500 & 0.938 & 0.283 & 0.654 \\
\hline 6.5500 & 0.938 & 0.189 & 0.749 \\
\hline 6.6500 & 0.931 & 0.189 & 0.742 \\
\hline 8.7000 & 0.292 & 0.075 & 0.216 \\
\hline 8.9000 & 0.292 & 0.038 & 0.254 \\
\hline 10.0000 & 0.278 & 0.000 & 0.278 \\
\hline 11.1500 & 0.271 & 0.000 & 0.271 \\
\hline 11.9500 & 0.132 & 0.000 & 0.132 \\
\hline 13.6000 & 0.000 & 0.000 & 0 \\
\hline
\end{tabular}

The test result variable(s): Uric acid has at least one tie between the positive actual state group and the negative actual state group. aThe smallest cutoff value is the minimum observed test value minus 1 , and the largest cutoff value is the maximum observed test value plus 1.

Table 4. Sensitivity and specificity values for uric acid in the diagnosis of cervical intraepithelial neoplasm.

\begin{tabular}{lc} 
& Uric acid \\
AUC & 0.841 \\
p-value & $<0.001$ \\
\hline Cut-off value & 6.55 \\
Sensitivity & 93.8 \\
\hline Specificity & 81.1 \\
PPV & 93.1 \\
\hline NPV & 82.7 \\
Prevalence & 73.1 \\
\hline Likelihood Ratio & 108.73 \\
LLA & 111.24 \\
Cramer's V & 0.75 \\
aOR & 64.50 \\
RR & 11.99
\end{tabular}


Table 5. Distribution of uric acid levels in study participant with cervical intraepithelial neoplasm and the control subjects according to age category.

\begin{tabular}{|c|c|c|c|c|}
\hline & & 53) & & \\
\hline & (n) & Uric acid (mg/dL) & (n) & Uric acid (mg/dL) \\
\hline $31-40$ years & 15 & $5.84 \mathrm{a}$ & 17 & $10.86 \mathrm{~b}$ \\
\hline $41-50$ years & 10 & $10.86 \mathrm{~d}$ & 32 & $7.71 \mathrm{a}$ \\
\hline $51-60$ years & 20 & $7.34 \mathrm{~b}$ & 56 & $10.14 b$ \\
\hline $61-70$ years & 8 & $9.18 \mathrm{c}$ & 10 & $7.97 \mathrm{a}$ \\
\hline$>70$ years & 0 & Nil & 29 & $8.30 \mathrm{a}$ \\
\hline F-statistc & & 19.649 & 8.73 & \\
\hline p-value & & $<0.001$ & $<0.001$ & \\
\hline
\end{tabular}

Although, in a study to determine the association of plasma uric acid levels with an endogenous oxidant in women with cervical intraepithelial neoplasia, it was reported that Plasma uric acid was significantly lower in women with CIN without any detectable alteration in the oxidized form. Findings in the present study disagree and provide evidence that elevated uric acid is a significant indicator of CIN. It was also suggested by the previously mentioned study that alteration in uric acid levels in women with CIN could not be attributed to abnormal renal function. ${ }^{11}$ The non-attribution of hyperuricemia in CIN patients to renal abnormality, was not covered in the scope of this study, though further investigation into the subject is suggested.

It has been documented that high levels of uric acid can promote the proliferation of cervical cancer cells, suggesting that uric acid may be a risk factor for this disease. ${ }^{6}$ The present study did not provide evidence to that claim but suggests that rapid turnover of cells and breakdown of nucleotides at the very early stage of a premalignant condition may be a risk factor for hyperuricemia. Consequently, as CIN progresses, hyperuricemia also progresses (Table 2) leading to cervical cancer. A retrospective meta-analysis examining 12 prospective studies spanning 632,472 subjects found that elevated uric acid levels were associated with increased risk of cancer mortality with a larger effect in females in a variety of cancers. $^{12}$

In the present study, a fraction of the subjects termed healthy ( 38 out of 53 women) by the Pap smear test were found to have increased uric acid levels. This may have been due to derangement in uric acid metabolism from any other cause. A previous study provided evidence of possible reasons for elevated serum uric acid. They found that patients with increased serum uric acid had increased rates of proteinuria, metabolic acidosis, osteoporosis, and anemia. ${ }^{13}$ Another study highlighted some hyperuricemic disorders such as gout, nephrolithiasis and cases of acute and chronic kidney disease. ${ }^{14}$

Apart from disorders correlated with hyperuricemia, increase in serum uric acid may also be as a result of pro antioxidants providing defensive guard for the system. It was hypothesized in 1981 that uric acid provides a primary defense against human cancer based on its capacity to scavenge free radicals and also inhibit lipid peroxidation. ${ }^{15}$ It is possible that the subjects in the current study with elevated uric acid levels without proof CIN lesions may have had physiological antioxidant function of uric acid. The protective antioxidant properties of uric acid have been identified in many different organ systems. ${ }^{16}$ Uric acid as a diagnostic marker in the current research was validated in comparison to the gold standard test (Pap smear) and it was found to be an excellent biomarker. It detected 145 women with CIN while Pap smear identified 144 women.
Table 6. Separation of the study population into subjects with cervical intraepithelial neoplasm and the control group using both serum uric acid and the gold standard.

\begin{tabular}{lccc} 
& CIN & Control & Total \\
By Gold standard & 144 & 53 & 197 \\
By Uric acid & 145 & 52 & 197 \\
\hline
\end{tabular}

\section{Study limitations}

The index study has some limitations. Firstly, most patients were unwillingly to participate in the study; however, this did not affect the quality of the study as the study protocol was followed strictly. Secondly, all the patients did not adhere to strict dietary control, which may affect the level of uric acid in the blood. Finally, the study did not control for other medications the patients may be on which also may affect uric acid levels.

\section{Conclusions}

This study suggest that serum uric acid level higher than 6.55 $\mathrm{mg} / \mathrm{d}$ is an indicator for the onset of cervical intraepithelial neoplastic lesions and may be used as an alternative to Pap smear test. However when uric acid is used for screening a population for CIN, a Pap smear should be employed secondarily to isolate true CIN patients from patients having hyperuricemia from other health conditions

\section{References}

1. Pisani P, Parkin DM, Bray F, Ferley J. Estimates of the worldwide mortality from 25 cancers in 1990. Int J Cancer 1999;83:870-3.

2. Ahmed SA, Sabitu K, Idris SH, Ahmed R. Knowledge, attitude and practice of cervical cancer screening among market women in Zaria, Nigeria. Nigeria Med J 2013;54:316-9.

3. Parkin DM, Bray F, Ferlay J, Pisani P. Global center statistics, 2002. CA Cancer J Clin 2005;55:74-108.

4. Ostor, AG. Natural history of cervical intraepithelial neoplasia: A critical review. Int J Gynecol Pathol 1993;12:186-92.

5. Wang S, Liu X, He Z, et al. Hyperuricemia has an adverse impact on the prognosis of patients with osteosarcoma. Tumour Biol 2018;37:1205-10.

6. Li C, Li Y, Su N, et al. Hyperuricemia predicts poor prognosis of patients with cervical cancer. Oncotarget 2018;9:537- 42.

7. Ara SA, Ashraf S, Patil BM. Evaluation of serum uric acid lev- 
els in patients with oral squamous cell carcinoma. Indian $\mathrm{J}$ Dent Res 2016;27:178-83.

8. Shin HS, Lee HR, Lee DC, et al. Uric acid as a prognostic factor for survival time: a prospective cohort study of terminally ill cancer patients. J Pain Symptom Manag 2006;31:493-501.

9. Zoppi F, Fenili D, Marcovina S, Peracino A. Aldehyde dehydrogenase interference in the Haeckel enzymic technique for uric acid determination. Clin Chem 1980;26:178.

10. Campbell G. Advances in statistical methodology for the evaluation of diagnostic and laboratory tests. Statistics Med 1994;13:499-508.

11. Basu J, Mikhail MS, Ahn CH, et al. Plasma uric acid levels in women with cervical intraepithelial neoplasia. Nutrition Cancer 2005;51:25-31.

12. Yan S, Zhang P, Xu W, et al. Serum uric acid increases risk of cancer incidence and mortality: asystematic review and metaanalysis. Mediators Inflamm 2015;2015:764250.

13. Yim K, Bindayi A, McKay R, et al. Rising serum uric acid level is negatively associated with survival in renal cell carcinoma. Cancers 2019;11:536.

14. Pacher P, Nivorozhkin A, Szabo C. Therapeutic effects of xanthine oxidase inhibitors: renaissance half a century after the discovery of allopurinol. Pharmacol Rev 2006;58:87-114.

15. Ames BN, Cathcart R, Schwiers E, Hochstein P. Uric acid provides an antioxidant defense in humans against oxidant- and radical-caused aging and cancer: a hypothesis. Proceedings of the National Academy of Sciences of the United States of America 1981;78:6858-62.

16. Becker BF. Towards the physiological function of uric acid. Free Radical Biol Med 1993;14:615-31. 